\title{
Risk assessment in postgraduate laboratories.
}

\author{
Omar Al-Obaidi², Mustafa Abdallh², Wedad H Al-Dahhan², Rahimi Yusop ${ }^{3}$, Ahmed Ahmed ${ }^{4}$, Emad \\ Yousif ${ }^{*}$ \\ ${ }^{1}$ Department of Chemistry, College of Science, Al-Nahrain University, Baghdad, Iraq \\ ${ }^{2}$ Department of Chemistry, Education College for Girls, University of Anbar, Anbar, Iraq \\ ${ }^{3}$ Faculty of Science and Technology, School of Chemical Sciences and Food Technology, University Kebangsaan \\ Malaysia, Selangor, Malaysia \\ ${ }^{4}$ Polymer Research Unit, College of Science, Al-Mustansiryah University, Baghdad, Iraq
}

\begin{abstract}
Chemistry laboratories in colleges or research centres in Iraqi universities are been widely used by both undergraduate and postgraduate students. Those institutes worked actively in reporting lab accidents and applying various procedures to improve the safety measures at these sites. In addition to many workshops was carried out to raise the awareness and encourage staff and students to apply safety standards and health conditions. This research is part of a series of studies that describe the status of laboratories, accidents, and laboratory improvements. This study summarizes the unsafe practices through monitoring the improper installation of equipment's and chemicals usage in one of the postgraduate laboratories in the chemistry department of an Iraqi university which can lead to many complications in the future. This research aims to reduce irregularities for a better workplace environment in other universities.
\end{abstract}

Keywords: Chemistry laboratories, Practice skills, safety, Potentials risks.

Accepted on September 06, 2018

\section{Introduction}

The laboratory is a place used to carry out scientific and practical activities. Teaching or research laboratories contains a dedicated and separate site as an office, a hardware room and a material preparation within the competence of the laboratory, which can be chemical, physical, biological or medical [1]. Working in such laboratories requires the application of approved safety procedures according to the nature of the laboratory, as well as rehabilitation courses for laboratory and student personnel, especially in the educational laboratories [2].

Academic and industrial laboratories require that they conform to basic safety principles to reduce injuries and accidents [3]. The laboratory must contain sufficient space and a special design according to the nature of the laboratory and equip the laboratories with appropriate furniture in addition to the availability of appropriate ventilation systems, lighting, heat control devices and dust disposal devices [4].

All personnel involved in the laboratory activity are responsible for safety as part of the administrative and ethical responsibility. All laboratory staff must meet the legal requirements of health, safety and the environment [5]. The existence of a large number of chemistry departments, research institutes and large number of researchers in Iraq, who are actively report the accidents occurring in their laboratories, in addition to various chemicals used in research in addition to lack of safety equipment makes it hard to control and manage the hazards. In order to minimize the potential health damage and improve the environmental impact of the chemical hazards.

Chemicals Safety and Security committees (CSSC) were established to ensure the safety performance standards in university facilities as well as individual researchers. The CSSC representatives inspected number of undergraduate and postgraduate laboratories at alternative campus of an Iraqi university.

The results discussed in this article and the outcome recommendation will be applied to other laboratories within the university. This article is a part of series of studies run by CSSC that will be published later.

\section{Alternative Campus}

Due the security issues related to the invasion of the western part of Iraq, there was a need to find an alternative campus for the students. The new place was a part of college at Baghdad. As a result of this urgent situation, the laboratories were designed according to the urgent needs of the Chemistry Department. Despite of the trials to meet the basic needs of the laboratories, the prompt renovation and construction project of the alternative location resulted in safety measures less than the standard requirements. Specially, safety measures related to chemistry department where the buildings are designed to have the laboratories very close to teaching rooms. Among these buildings are laboratories that include vacuum hoods used in 
the graduate lab for master's students (Figure 1). The students in this laboratory are more likely to be influenced by this faulty fume hood. Many of these shortages have been reported in our previous reports [6-10].

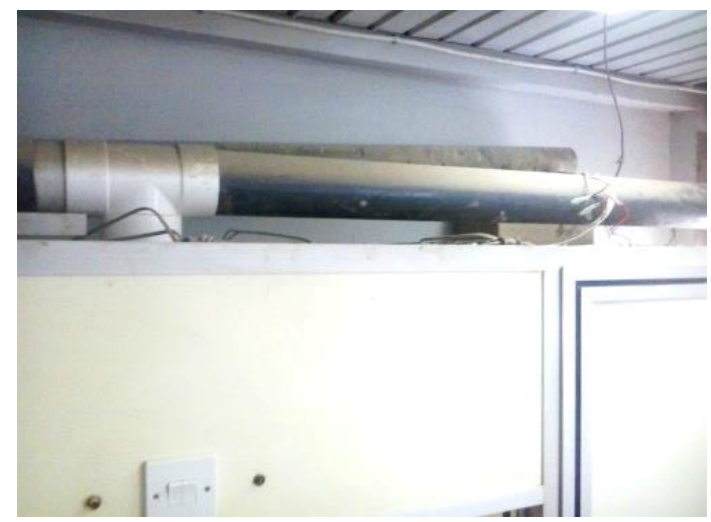

Figure 1: Improperly installation of fume hood can make a number of risks to postgraduate students.

\section{Assessment Results}

After careful assessment of the laboratories in chemistry department including the postgraduate laboratories taking into consideration to make use of some established strategies from the literatures [11-19]. CSSC inspectors found many dangerous faults in those laboratories (Figures 1-4).

1. Not enough space for the fume hood in the lab (Figure 1).

2. The ventilation and the gas system were incorrectly installed, which may cause gas leakage (Figure 2).

3. The design of the light system was installed randomly.

4. No laboratory operating instructions.

5. Air conditioning has been installed in a separate unit installed rather than central air conditioning (Figure 3).

6. Liquid and solid chemicals were used and stored in random containers (Figure 4).

7. Connections, pipes and water pipes are made of materials that do not conform to laboratory standards (Figure 5).

8. No information regarding the chemicals stored in the cupboard (Figure 6).

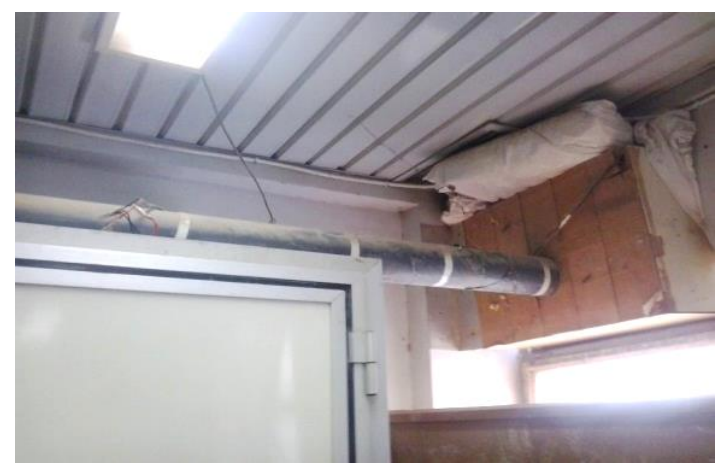

Figure 2: Incorrect installation of gas and vapours tubes which may lead to leakage.

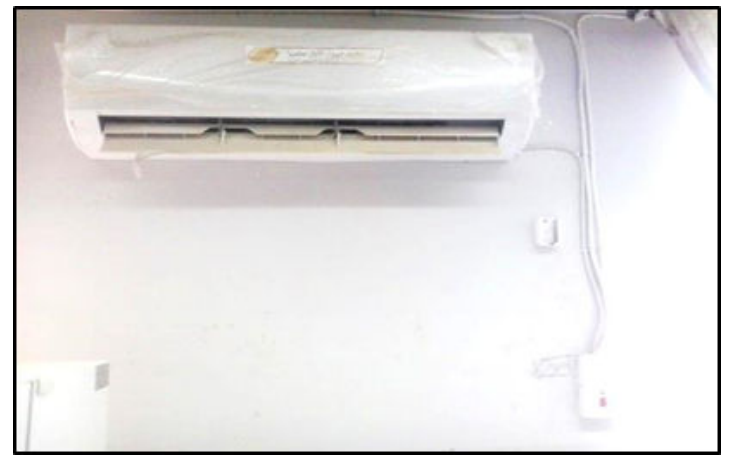

Figure 3: Air conditioning unit is separate and not central.

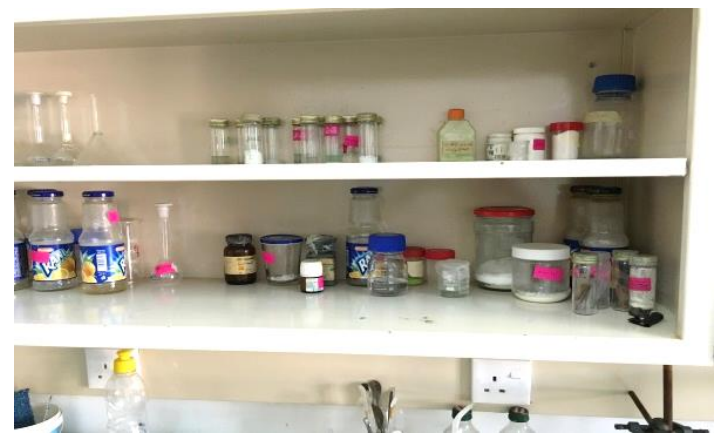

Figure 4: Use of chemicals and their storage in random containers.

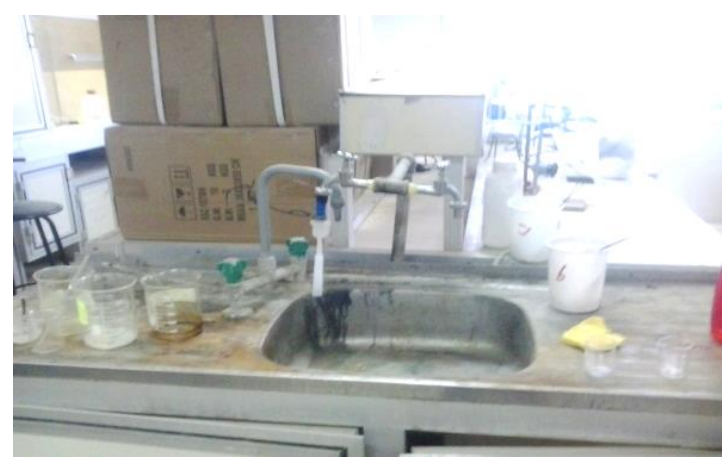

Figure 5: Connections, water pipes and pipes from materials not complying with laboratory specifications.

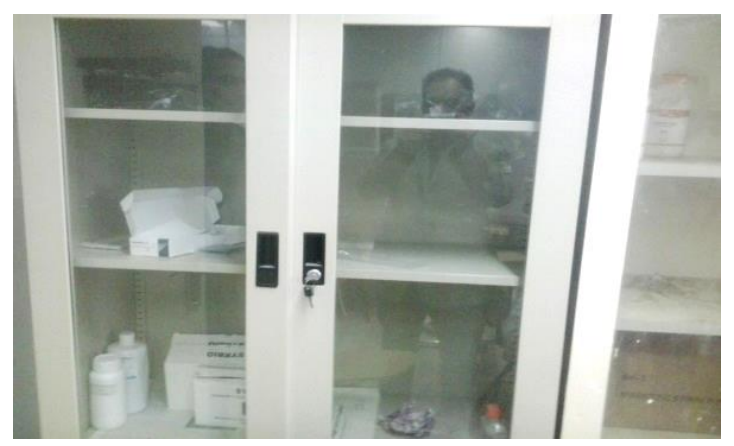

Figure 6: No information regarding the chemicals stored in the cupboard.

\section{Lessons Learned}

Based on the results, CSSC recommends stopping the work on that laboratory and forbidding the use by student or staff till all safety issues are fixed. 
In addition to the safety issues on that specific lab, this study raise concerns regarding the safety in all other laboratories. Thought, there is no accident of any kind (i.e. fire and/or suffocation) have been reported but these observations and concerns have contributed to the safety and security situation in the Graduate Laboratory. For the future safety, CSSC recommended:

1. Safety and security measures must be taken before commencing the refurbishment or installation of equipment in any postgraduate laboratory. This applied to undergraduate laboratories studies as well.

2. For any future construction or development process, the design of the construction site must be planned in advance. This must include proper training and clear understanding of all chemical-related safety systems, including the function of equipment and associated materials suitable for use in the laboratory, CSSC shall participate in supervision and control in execution until received by the final beneficiary.

3. Hazardous gases, especially for undergraduate laboratories, must be connected to well install fume hood to minimize students' exposure to such dangerous gases.

4. Pipes must properly install to reduce the possibility of leakage of gases and volatile vapours.

5. Periodic maintenance and evaluation of electrical connections required.

6. Replacing the split unit air conditioning system with central one to reduce the dangerous of sparks who may cause a fire and to ensure that the gases are not recycled in the laboratory.

7. Fume hood draining system must be separated from the sewage system of the building.

8. Clear labelling system of chemicals in addition to the use of proper storing containers needed.

\section{Discussions and Conclusions}

This case study highlighted the safety issues related to the urgent installation of postgraduate laboratories which might lead to serious and dangerous damages including lost in life. Thus, CSSC audited and assessed the systematic risk to prevent the hazards and damages and to educate student about the chemical hazards associated with their work. It is useful to consult with CSSC before starting any refurbishment and construction to design safe workplace and to avoid and reduce risks completely. We hope that this study give the inspiration for other researchers and institute to follow the proper safety measures and to avoid all the possible damages.

One of a complex learning location is the instructional chemistry laboratory. The laboratory area must be cautiously planned in order to give a significant knowledge for learners inside this atmosphere, in the status of the related course. So, the material services need care and match the educational objectives. This connection is obvious in the strategies that were applied to the renovation development that is reported here.
Assignments at different organizations are certainly working to be exclusive in their character founded on their institutional tradition. To the level that goals are engaged, a certain sharing points of features will also stand out. It is well known that the sharing of understandings between organizations tells upcoming approaches and improves products. So, in this process of development of laboratory design, motivated together by the alterations in the chemical sciences and in related alterations in education. We wish that our involvements give towards the continual development in the strategy and use of instructional chemistry workrooms in our country.

\section{References}

1. http://sydney.edu.au/whs/guidelines/others/ laboratory_safety.shtml

2. Hill, Robert H Jr, David C Finster. Laboratory safety for chemistry students. Wiley, Hoboken, 2010.

3. Prudent practices in the laboratory, the national academies press, Washington, 2015. A comprehensive study of laboratory safety issues including leadership and management considerations.

4. Guidelines for recognition of environmental laboratories under the environment (protection) Act, 1986, Central Pollution Control Board (Ministry of Environment \& Forests).

5. Laboratory safety handbook, McMaster University Hamilton, Ontario, 2008.

6. Al-Zuhairi A, Al-Dahhan W, Hussein F, et al. Teaching Laboratory Renovation, Orient J Phys Sciences. 2016;1:31-5.

7. Ali A, Shaalan N, Al-Dahhan W, et al. For a safer working environment with hydrofluoric acid in iraqi industrial plants. Open J Safety Sci Technol. 2016;6:77-80.

8. Rasool S, Al-Dahhan W, Al-Zuhairi A, et al. Fire and explosion hazards expected in a laboratory, J Lab Chem Edu. 2016;4:35-7.

9. Ali A, Al-DahhanW, Zageer D, et al. A vision to promote the forensic DNA facility at Al-Nahrain University in terms of safety measures. Orient J Phys Sciences. 2017;2:37-41.

10. Ali A, Shaalan N, Al-Dahhan W, et al. A technical evaluation of a chemistry laboratory: A step forward for maintaining safety measures. Orient J Phys Sciences. 2017;2:68-71

11. Hussein F, Al-Dahhan W, Al-Zuhairi A, et al. Maintenance and testing of fume cupboard. Open J Safety Sci Technol. 2017; 7: 69-75.

12. Al-Zuhairi A Hazard analysis and critical control point HACCP system. Iraqi National J Chem. 2016;16:172-85.

13. Yousif E, Al-Dahhan W, Abed R, et al. Improvement of a chemical storage room ventilation system. J Progressive Res Chem. 2017;3:206-10.

14. Yousif E, Al-Dahhan W, Ali A, et al. Mind what you put in a furnace: A case study for a laboratory incident. J Environ Sci Public Health. 2017;1: 56-61. 
15. Al-Dahhan W, Al-Zuhairi A, Hussein F, et al. Laboratory biological safety cabinet (BSC) explosion. Karbala Int $\mathrm{J}$ Modern. 2016;2:276-79.

16. Al-Dahhan W, Al-Zuhairi A, Yousif E, et al. Bad filling ionic liquid sample in split tube furnace. Interdiscip $\mathrm{J}$ Chem. 2017;2:1-3.

17. Al-Dahhan W, Ali A, Yousif E, et al. Lack of maintenance in a chemical laboratory has almost caused an accident. Open J Chem. 2017;1:63-6.

18. Al-Dahhan W, Ali A, Jasim A, et al. Evaluating a chemical/ biological laboratory to promote safety measures. Orient J Physic Sciences. 2017;2:95-102.

19. Al-Dahhan W, Ali A, Yousif E, et al. Environmental problem from the combustion of sulphur in Mishraq field. Special J Chem. 2017;2:10-6.

\section{*Correspondence to}

Emad Yousif

Department of Chemistry

College of Science

Al-Nahrain University, Baghdad, Iraq

E-mail: emad_yousif@hotmail.com 